\title{
COMPORTAMENTO DO DICLOSULAM EM AMOSTRAS DE UM LATOSSOLO VERMELHO DISTROFÉRRICO SOB PLANTIO DIRETO E CONVENCIONAL ${ }^{(1)}$
}

\author{
A. LAVORE NTI (2), A. A. ROCHA(3), F. PRATA ${ }^{(4)}$, J . B. REGITANO(5), \\ V. L. TORNISIE LO ${ }^{(5)} \&$ O. B. PINTO(6)
}

\begin{abstract}
RESUMO
O objetivo deste estudo foi verificar a dissipação, efeito na microbiota e sorção/dessorção do ${ }^{14} \mathrm{C}$-diclosulam num Latossolo Vermelho distroférrico cultivado há 10 anos sob plantio direto (PD) ou convencional (PC). Foram realizados três ensaios paralelos: dissipação, sorção/dessorção, atividade microbiana. Nos ensaios de dissipação e sorção/dessorção, os tratamentos consistiram na aplicação de diclosulam a amostras de solo oriundas de dois sistemas de preparo de solo; no experimento de atividade microbiana, testou-se a aplicação ou não do herbicida em amostras dos dois sistemas. 0 ensaio de dissi pação foi realizado em frascos de Bartha, com avaliação semanal da mineralização do herbicida por radiorrespirometria. Nos mesmos períodos de avaliação, em outros frascos, foram extraídos o herbicida e seus metabólitos e, subseqüentemente, foi quantificada a fração remanescente no solo (fração resíduo ligado) após oxidação em oxidador biológico. A atividade microbiana do solo foi avaliada por meio da técnica da ${ }^{14} \mathrm{C}$-glicose. Nas i sotermas de sorção/ dessor ção, utilizaram-se cinco concentrações do her bicida e quatro dessorções para cada concentração. O sistema plantio direto acelerou a dissipação do diclosulam no solo, conforme a maior atividade microbiana, e a maior formação de resíduo ligado, relativamente ao sistema convencional. A extração do herbicida diminuiu com o tempo, graças à metabolização e ao aumento na formação da fração resíduo ligado. O diclosulam apresentou baixa taxa de sorção, independentemente do sistema de manejo. A aplicação do diclosulam não interferiu na atividade microbiana do solo. 0 sistema de manejo interferiu na dissipação do diclosulam no solo.
\end{abstract}

Termos de indexação: degradação, sorção, dissi pação, mineralização, resíduo ligado, radiorrespirometria.

\footnotetext{
(1) Recebido para publicação em junho de 2001 e aprovado em outubro de 2002.

(2) Professor Associado, Departamento de Ciências Exatas - Escola Superior de Agricultura "Luiz de Queiroz" - ESALQ/USP. Caixa Postal 9, CEP 13418-900 Piracicaba (SP). E-mail: alavoren@carpa.ciagri.usp.br

(3) Engenheiro-Agrônomo, Mestre em Solos e Nutrição de Plantas, ESALQ/USP. E-mail: aderbalrocha@ig.com.br

(4) Engenheiro-Agrônomo, Doutor em Solos e Nutrição de Plantas, ESALQ/USP. E-mail: fabioprata@bioagri.com.br

(5) Pesquisador, Laboratório de Ecotoxicologia - CENA/USP. Caixa Postal 96, CEP 13400-970 Piracicaba (SP). E-mails: regitano@cena.usp.br; vitornis@cena.usp.br

(6) Dow AgroSciences, Rodovia SP 147 Km 71,5 Caixa Postal 226, CEP 13800-970 Mogi Mirim (SP). E-mail: obalderrama@dow.com
} 


\title{
SUMMARY: REACTIONS OF DICLOSULAM IN A RHODIC HAPLUDOX SOIL UNDER NO-TILL AND CONVENTIONAL TILLAGE SYSTEMS
}

\begin{abstract}
The aim of this study was to evaluate the dissipation, effects on microorganisms, and sorption/ desorption of ${ }^{14} \mathrm{C}$-diclosulam in Rhodic Hapludox soil samples, cultivated for 10 years under no-till (NT) or conventional tillage (CT) systems. We carried out three individual experiments. In thedissipation and sorption/ desorption experiments, dicl osulam was applied to soil samples of both management systems. Themicrobial activity experiment tested diclosulam application and non-application on the soil samples. The degradation experiment was carried out in Bartha flasks, weekly evaluating herbicidemineral izati on by radiorespi rometry. In a paralle evaluati on, theherbi cideand its metabol ites wer eextracted in other flasks, and theremaining fraction in thesoil (bound-residuefraction) was quantified after oxidation in a biological oxidizer. The microbial activity was evaluated by the ${ }^{14} \mathrm{C}$-gl ucose technique In order to obtain the sorption/ desorption isotherms, we empl oyed five herbicide concentrations, with four desorptions each. Didlosulam dissipation in the soil was accelerated by the no-till system, due to a higher microbial activity as well as a higher bound-residue formation, compared to the conventional system. The herbicide extraction decreased with time, dueto metabolization and theincreasein thebound-resi due formation. Diclosulam presented a low sorption rate, independently of the management system. Diclosulam application was no hindrance for microbial soil activity, but the management systems did interfere with the dissipation of diclosulam in the soil.
\end{abstract}

Index terms: degradation, sorption, dissipation, mineralization, bound residue, radiorespirometry.

\section{INTRODUÇÃO}

A descoberta do poder de algumas substâncias organossintéticas para o controle de agentes indesejáveis ou nocivos, como insetos, fungos, plantas daninhas, etc., proporcionou a expansão das áreas cultivadas e o aumento da produção de alimentos em todo o mundo. Em menos de quarenta anos, esses produtos químicos de utilização agronômica tornaram-se os insumos mais utilizados na produção agrícola de larga escala, tendo-se intensificado em meados dos anos setentas.

Quando um herbicida é aplicado no ambiente e atinge o solo, suas moléculas podem seguir diferentes rotas. Elas podem ser sorvidas aos colóides minerais e orgânicos e, dependendo da energia de ligação, podem-se tornar indisponíveis às plantas (fração resíduo ligado) ou ser novamente dessorvidas à solução do solo (Hornsby et al., 1995, Lavorenti, 1997).

Segundo Führ (1997), resíduo ligado é o nome dado à interação de espécies químicas originadas da transformação ou não de pesticidas com uma matriz (solo, planta ou animal), não sendo estes resíduos passíveis de extração por métodos que não alterem significativamente a natureza da molécula e da matriz. As moléculas podem também ser transformadas em metabólitos, normalmente de menor massa molecular, num processo conhecido como degradação. Os produtos finais da degradação são $\mathrm{CO}_{2}, \mathrm{H}_{2} \mathrm{O}$ e íons (Bollag \& Liu, 1990). As moléculas, quando apresentam baixa tendência à formação de resíduo ligado e são pouco degradadas, tendem a permanecer na solução do solo, podendo ser absorvidas por raízes de plantas ou lixiviadas para camadas subsuperficiais do perfil. Tudo isso ocorre simultaneamente, em intensidades diferentes, e depende das propriedades físico-químicas do herbicida, do solo e dos fatores climáticos (Bollag \& Liu, 1990; Hornsby et al., 1995). As frações mineralizadas, metabol izadas e os resíduos ligados de um pesticida no solo constituem a fração dissipada de suas moléculas.

O diclosulam [N-(2,6-diclorofenil)-5-etoxi-7-fluor$(1,2,4)$ triazol o(1,5-c)pirimidina-2-sulfonamida] (Figura 1) é um herbicida pertencente ao grupo químico das triazolpirimidina sulfonanilidas, amplamente utilizado no Brasil, Argentina e Estados Unidos (Yoder et al., 2000). No Brasil, este herbicida passou a ser usado na safra 97/98, com a finali dade de control ar dicotiledôneas na cultura da soja. Ele é aplicado em pré-plantio incorporado ou em pré-emergência, atuando na inibição da enzima acetolactato sintetase (ALS) (Rodrigues \& Almeida, 1998). E ssa enzima está localizada no cloroplasto, onde catalisa a condensação de duas moléculas de piruvato em acetolactato, o qual é convertido em valina eleucina. U ma reação similar, que produz a acetoidroxibutirato, responsável pela biossíntese da isol eucina, também é catalisada pela ALS, quando a $\alpha$-ketobutirato e o piruvato são usados como substrato (Singh \& Shaner, 1995). 


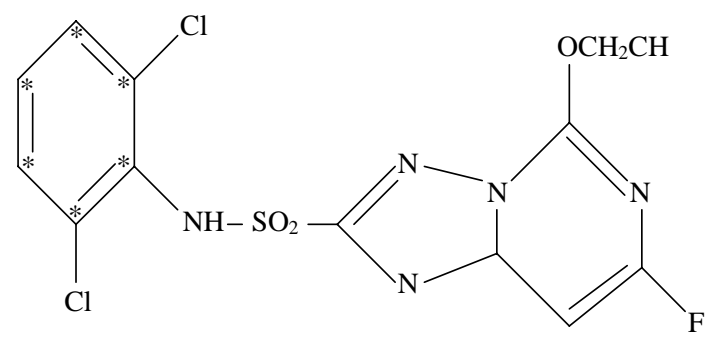

Figura 1. Fórmula estrutural da molécula do herbicida diclosulam. * Posição do ${ }^{14} \mathrm{C}$. Fonte: Yoder et al. (2000).

A aplicação do diclosulam, quando comparada com a de outros herbicidas, ocorre em doses muito baixas, variando de 25 e a $35 \mathrm{~g} \mathrm{ha}^{-1}$ de ingrediente ativo (Rodrigues \& Almeida, 1998). No entanto, de acordo com Yoder et al. (2000), a aplicação desse herbicida na soja poderia vir a causar injúrias em culturas subseqüentes, como o milho. Por esta razão, Rodrigues \& Almeida (1998) evidenciam que áreas tratadas com diclosulam não devem ser cultivadas com girassol e brássicas.

E mbora Yoder et al. (2000) tenham observado rápida metabolização do diclosulam em solos argentinos, brasileiros e norte-americanos $\left(t_{1 / 2}\right.$ $<30$ dias), esse herbicida e seus metabótitos apresentam valores de coeficiente de partição $\left(K_{\mathrm{d}}\right)$ bastante baixos, o que mostra um potencial de movimentação vertical, facilitada pela solubilidade em água, $\mathrm{p} K_{\mathrm{a}}$, e coeficiente de partição octanol/água $\left(K_{\text {ow }}\right)$. A solubilidade do diclosulam em água é dependente do $\mathrm{pH}$ e varia de $\sim 100 \mathrm{mg} \mathrm{kg}^{-1} \mathrm{em} \mathrm{pH}$ entre 5 e 7 e $>4.000 \mathrm{mg} \mathrm{kg}^{-1} \mathrm{em} \mathrm{pH} 9$. O $\mathrm{p} K_{\mathrm{a}}$ da molécula é de 4,09 a $20 \stackrel{\circ}{\circ}$, indicando sua predominância na forma aniônica em valores depH característicos de sol os agricultáveis. Seus valores de $\log K_{\text {ow }}$ variam de $-0,448$, em pH 9, a 1,42, em $\mathrm{pH} 5$, indicando também baixa hidrofobicidade (Yoder et al., 2000).

Pelo fato de ser o diclosulam uma molécula recente no mercado brasileiro e mundial, praticamente não existem estudos referentes ao seu comportamento no solo. Desta forma, o presente estudo teve como objetivo verificar a dissipação, efeito na mi crobiota esorção/dessorção do dicl osulam num Latossolo Vermel ho distroférrico cultivado há dez anos sob plantio direto ou convencional .

\section{MATERIAL E MÉTODOS}

Este trabal ho constou de três experimentos. No primeiro, avaliou-se a dissipação (mineralização, metabol ização e formação da fração resíduo ligado) do diclosulam. O segundo experimento foi realizado com o objetivo de verificar tanto o efeito dos sistemas de manejo de solo quanto da aplicação ou não do didosulam na atividade microbiana do sol o. O último ensaio foi o de sorção/dessorção.

Foram coletadas amostras entre $0-10 \mathrm{~cm}$ de profundidade, de um LatossoloVermel ho distroférrico argil oso da região de Piracicaba (SP), cultivado há dez anos sob plantio direto (PD) ou convencional (PC), em áreas adjacentes. As amostras foram passadas em peneira com malha de $2 \mathrm{~mm}$ e subdivididas em duas: uma parte foi armazenada por 15 dias em geladeira $\left(+5^{\circ} \mathrm{C}\right.$ ), para posterior utilização nos experimentos de degradação e atividade microbiana, enquanto a outra foi seca ao ar para a utilização no ensaio de sorção/dessorção. As análises químicas egranul ométricas do sol o foram realizadas de acordo com Raij \& Quaggio (1983) e Camargo et al. (1986), respectivamente (Quadro 1).

Nos ensaios de dissi pação e sorção/dessorção, foi utilizada uma mistura do diclosulam grau técnico e seu isótopo radioativo ${ }^{14} \mathrm{C}$-did osulam, uniformemente marcadonoanel did orofenil (Figura 1). As moléculas apresentaram pureza analítica superior a $97 \%$ e a atividade específica do ${ }^{14} \mathrm{C}$-diclosulam foi de $1050,8 \mathrm{MBq} \mathrm{mmol}^{-1}$.

\section{Estudo de dissi pação}

O ensaio de dissipação foi realizado em delineamento inteiramente casualizado, com duas repetições, para as avaliações de mineralização, e duas repetições por período de avaliação (frascos sacrificados após cada período de avaliação), para as avaliações de metabolização e resíduo ligado. Os tratamentos consistiram na aplicação do di cl osulam a amostras de sol o provenientes deáreas com plantio direto (PD) ou convencional (PC).

Quadro 1. Atributos químicos e granulométricos do Latossolo Vermelho cultivado há 10 anos sob plantio direto (PD) ou convencional (PC)

\begin{tabular}{|c|c|c|c|c|c|c|c|c|c|c|c|c|}
\hline $\begin{array}{l}\text { Sistema de } \\
\text { manejo }\end{array}$ & $\mathrm{pH}-\mathrm{CaCl}_{2}$ & C org. & $\mathbf{P}$ & K & $\mathrm{Ca}$ & Mg & Al & $\mathbf{H}+\mathbf{A l}$ & CTC & Areia & Silte & Argila \\
\hline & & $\mathrm{g} \mathrm{dm}^{-3}$ & $\mathrm{mg} \mathrm{dm}^{-3}$ & 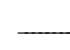 & 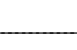 & $-m n$ & $\mathrm{cdm}^{-}$ & . & - & 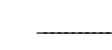 & $\mathrm{g} \mathrm{kg}^{-1}$ & - \\
\hline PD & 5,0 & 19,9 & 21 & 5,6 & 48 & 24 & 0 & 42 & 119,6 & 445 & 200 & 355 \\
\hline PC & 4,4 & 12,8 & 17 & 3,2 & 36 & 13 & 3 & 52 & 104,2 & 485 & 174 & 341 \\
\hline
\end{tabular}


As parcelas foram constituídas por frascos de Bartha (Bartha \& Pramer, 1965) com $80 \mathrm{~g}$ de solo (base seca), aos quais foi aplicado o diclosulam $\left(0,145 \mu \mathrm{g} \mathrm{g}^{-1}\right)$ com radioatividade de aproximadamente $0,167 \mathrm{kBq} \mathrm{g}^{-1}$. A concentração aplicada foi correspondente a 2,5 vezes à dose recomendada no campo, considerando como base de cálculo $5 \mathrm{~cm}$ de profundidade e densidade do sol o igual a $1,2 \mathrm{~g} \mathrm{~cm}^{-3}$. O tempo do experimento foi de 119 dias, com as avaliações de desprendimento de ${ }^{14} \mathrm{CO}_{2}$ realizadas aos 2, 7, 14, 21, 28, 35, 42, 49, 63, 77, 91, 105 e 119 dias da aplicação do diclosulam. Para a col eta do ${ }^{14} \mathrm{CO}_{2}$, foi utilizada solução de $\mathrm{NaOH} 2 \mathrm{~mol} \mathrm{~L}^{-1}$. Durante o período do ensaio, a umi dade do sol o foi mantida em $60 \%$ da capacidade de campo, e o ambiente foi mantido escuro, a $25 \pm 2{ }^{\circ} \mathrm{C}$.

Em cada período de avaliação, foram feitas duas outras repetições, nas quais foram realizadas as extrações do herbicida e de seus metabólitos, bem como a oxi dação da fração no sol o remanescente após a extração (fração resíduo ligado). A extração foi feita em duas etapas, utilizando-se como extrator uma mistura composta de acetona e $\mathrm{HCl} 0,1 \mathrm{~mol} \mathrm{~L}^{-1}$ (9:1) para uma relação solo: solução de 1:4. Cada etapa foi constituída de agitação a 200 rpm, por duas horas, seguida de centrifugação a 12.000 rpm por $15 \mathrm{~min}$. Os dois extratos foram misturados e a radioatividade foi determinada por espectrometria de cintilação líquida (ECL), em alíquotas de $0,5 \mathrm{~mL}$. Posteriormente, os extratos foram concentrados a $15 \mathrm{~mL}$, em rotavapor a $40 \stackrel{\circ}{\mathrm{C}}$, e alíquotas de $200 \mu \mathrm{L}$ (duas para cada extrato) foram utilizadas para a elaboração de placas de cromatografia em camada delgada (TLC). O solvente empregado na eluição das placas foi uma mistura de tolueno, acetonitrila eácidoacético glacial (50:45:5). Os valores derelação de frente $\left(R_{F}\right)$ dos metabólitos foram determinados em "radio-scanner" e quantificados pela integração dos picos.

Subseqüentemente, quatro alíquotas de $300 \mu \mathrm{g}$ do solo residual de cada extração foram oxidadas em oxidador biológico, para a verificação da fração resíduo ligado do dicl osulam, sendo a radioatividade determinada por ECL.

O somatório do diclosulam mineralizado, metabolizado e remanescente no solo após as extrações (resíduo ligado) representou a fração dissi pada do herbicida no sol o durante os 119 dias. Aos valores de dissipação foi aplicado o modelo de cinética de primeira ordem (Sparks, 1989):

$$
C=C_{0} e^{k t}
$$

em que $C$ éa concentração de diclosulam no tempo $t$, $C_{0}$ éa concentraçãototal de did osulam notempozero, $k$ é a constante de velocidade de dissi pação $\left(\right.$ dia $\left.^{-1}\right)$ e $t$ o tempo de incubação (dia).

A meia-vida $\left(t_{1 / 2}\right)$ foi calculada por meio da linearização da equação supradescrita:

$$
t_{1 / 2}=\frac{\ln 2}{k}
$$

\section{Estudo de atividade microbiana}

O objetivo específico deste experimento foi explicar os possíveis resultados obtidos no ensaio de dissipação, além de verificar se o diclosulam pode provocar algum efeito na microbiota heterotrófica do solo.

Paralelamente, e nos mesmos moldes do experimento de dissi pação, foi desenvol vi do o estudo deatividade mi crobiana. Nesse ensaio, foi utilizado del ineamento intei ramente casual izado em arranjo fatorial $(2 \times 2)$, tendo como fatores amostras de solo oriundas dos sistemas de cultivo (PD e PC) e a aplicação ou não do herbicida.

A concentração de diclosulam foi idêntica à usada no estudo de degradação, porém foi utilizado o diclosulam técnico. Os períodos de avaliação foram realizados aos 0, 2, 7, 14, 28, 63, 91 e 119 dias da aplicação do herbicida, enquanto a atividade microbiana foi determinada deacordo com o método da ${ }^{14} \mathrm{C}$-glicose (Freitas et al., 1979). Foram feitas análises de variância para cada período de avaliação, além de teste de comparação de médias entre os tratamentos (Testet, $\mathrm{p}<0,05$ ).

\section{Estudo de sorção/dessorção}

O experimento de sorção/dessorção foi realizado de acordo com a técnica "batch" (Sparks, 1989), em delineamento intei ramente casualizado, com três repetições, em que os tratamentos consistiram na aplicação de várias concentrações do herbicida a amostras provenientes de PD ou PC. No entanto, para a realização do estudo de isotermas, foram utilizadas, para cada tratamento, cinco sol uções com diferentes concentrações de diclosulam: 0,057; 0,114; 0,$228 ; 0,456$ e $0,912 \mathrm{mg} \mathrm{L}^{-1}$. A concentração de $0,057 \mathrm{mg} \mathrm{L}^{-1}$ correspondeu a 2,5 vezes a dose recomendada para as lavouras, considerando como base de cálculo a profundidade do solo de $5 \mathrm{~cm}$ e densidade de $1,2 \mathrm{~g} \mathrm{~cm}^{-3}$. As soluções foram preparadas em $\mathrm{CaCl}_{2}$ 0,01 mol L-1, empregando-se tanto o produto técnico como seu isótopo radioativo $\left(0,133 \mathrm{kB} \mathrm{q} \mathrm{mL}^{-1}\right)$. Amostras de 2 g de solo ealíquotas de $5 \mathrm{~mL}$ de solução foram acondicionadas em tubos de centrífuga ( $50 \mathrm{~mL}$ ), os quais foram agitados horizontal mente (200 rpm), durante $24 \mathrm{~h}$, a $25 \pm 2{ }^{\circ} \mathrm{C}$. Subseqüentemente, o conteúdo suspenso nos tubos foi centrifugado (10.000 rpm, por $15 \mathrm{~min}$ ), retirandose uma alíquota de $1 \mathrm{~mL}$ do sobrenadante para determinação, por ECL, da concentração de diclosulam na solução de equilíbrio $\left(C_{\mathrm{e}}\right)$. A quantidade sorvida ao solo foi determinada por diferença entre a concentração inicial e a concentração na solução de equilíbrio.

Os testes de dessorção foram aplicados em todas as concentrações empregadas no estudo de sorção. 
Para tal, os sobrenadantes dos tubos de centrífuga foram descartados e alíquotas de $5 \mathrm{~mL}$ de solução de $\mathrm{CaCl}_{2} \quad 0,01 \mathrm{~mol} \mathrm{~L}^{-1}$ foram adicionadas. Posteriormente, os tubos foram agitados, centrifugados e o novo sobrenadante foi descartado da mesma forma que no teste de sorção. Este procedimento foi repetido por mais três vezes, após o qual as amostras de solo foram secas ao ar, homogeneizadas e retiradas subamostras $(0,4 \mathrm{~g})$, com vistas em determinar a radioatividade na fração sorvida do herbicida por meio deECL, após combustão em oxidador biológico, o que permitiu ofechamento do balanço de massa radioativa. Com duas alíquotas da solução de equilíbrio de al gumas amostras, após a última dessorção, foram preparadas placas deTLC, as quais foram verificadas em "radio-scanner". Nelas, não foram detectados metabólitos, o quevalida o teste de sorção/dessor ção da mol écula original.

No cál culo das constantes de sor ção e dessorção, foi utilizado o model o matemático de Freundlich:

$$
S=K_{f} C_{e}^{N}
$$

em que $S=$ concentração de diclosulam sorvido $\left(\mu \mathrm{g} \mathrm{g}^{-1}\right), C_{e}=$ concentração de diclosulam na solução de equilíbrio $\left(\mu \mathrm{g} \mathrm{mL}^{-1}\right), K_{f}=$ constante de sorção ou dessorção de Freundlich e $N=$ grau de linearidade da isoterma.

As constantes de sorção linear $\left(K_{d}\right)$ e a normalizada para a matéria orgânica $\left(K_{o c}\right)$ foram calculadas por meio das seguintes equações:

$$
\begin{gathered}
K_{d}=\frac{S}{C_{e}} \\
K_{O C}=\frac{K_{d}}{C_{\text {org }}} 10
\end{gathered}
$$

em que $C_{\text {org }}$ éo conteúdo de carbono orgânico do solo $\left(\mathrm{g} \mathrm{kg}^{-1}\right)$. Para tal, foram utilizados os valores médios de $K_{\mathrm{d}}$ para as cinco concentrações.

A partir dos valores de $t_{1 / 2}$ e $K_{o c}$ calculou-se a estimativa do potencial delixiviação pel oíndice GUS (Gustafson, 1989):

$$
G U S=\ln t_{1 / 2}\left(4-\ln K_{o c}\right)
$$

\section{RESULTADOS E DISCUSSÃO}

Após 119 dias da aplicação do diclosulam ao solo, as taxas de mineralização foram de 13,9 e $11,2 \%$, as de metabolização de 29,6 e 27,4 \%, eas de formação de resíduo ligado de 29,1 e 23,4 \%, o que resultou em 73 e $62 \%$ de dissipação do herbicida para amostras oriundas dos sol os cultivados sob PD ePC, respectivamente (Figura 2). Desta forma, com aplicação do modelo de cinética de primeira ordem para a dissipação (Sparks, 1989), observaram-se valores de meia-vida $\left(t_{1 / 2}\right)$ do diclosulam de 67 dias, para oPD, e de 87, para oPC (Figura 2a). De acordo com a dassificaçãoutilizada pel ol nstituto Brasileiro do Meio Ambiente (IBAMA) para persistência de pesticidas no solo, esses valores caracterizam o diclosulam como uma molécula de persistência "reduzida" ( $t_{1 / 2}$ entre 30 e 90 dias) (Brasil, 1988). Todavia, a magnitude dos valores de $t_{1 / 2}$ obtidos neste trabalho foi superior à apresentada por Yoder et al . (2000) para solos paranaenses, argentinos e americanos, os quais variaram de 16 a 54 dias.
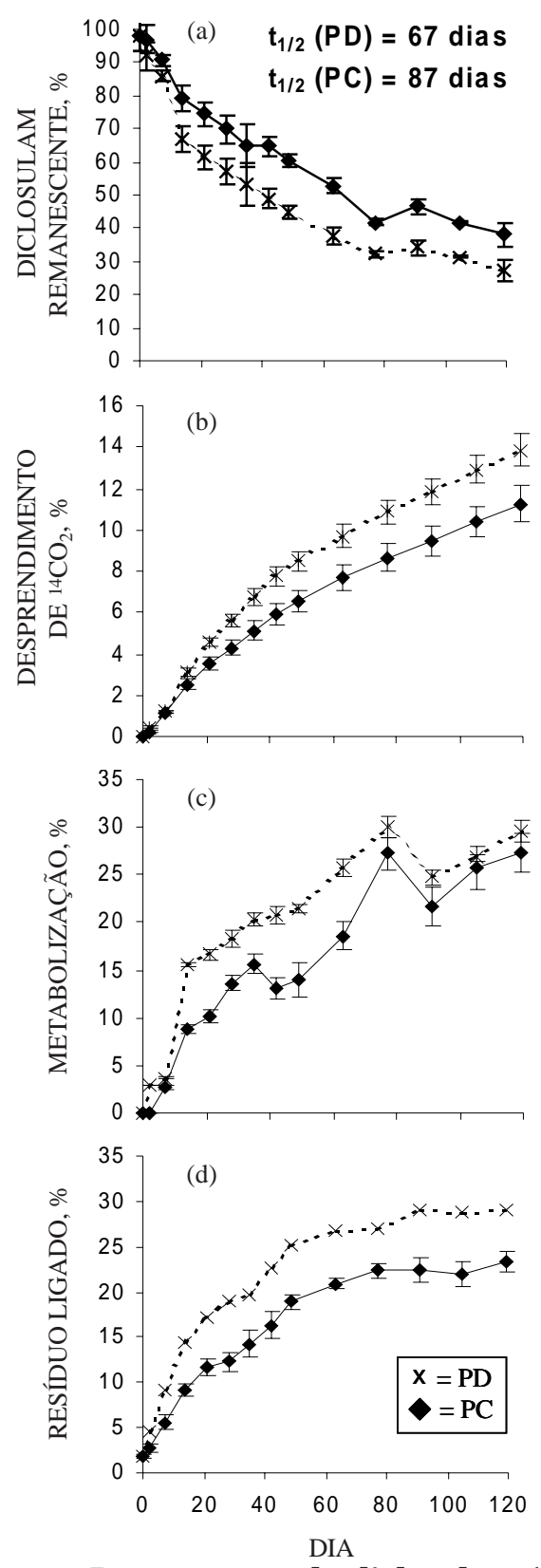

Figura 2. Percentagem de diclosulam (a) remanescente, (b) mineralizado, (c) metabolizado e (d) na forma de resíduo ligado e remanescente no Latossolo Vermel ho distrofér rico cultivado há 10 anos sob plantio direto (PD) ou convencional (PC). As barras verticais correspondem ao desvio-padrão da média. 
A maior atividade microbiana no PD (Figura 3a) do que no PC está, provavel mente, relacionada com os maiores conteúdos de $C$ orgânico e nutrientes nesse sistema (Quadro 1) e pode explicar, em parte, a maior taxa de degradação (mineralização + metabolização, Figuras 2B e 2C) do diclosulam no PD, pois a principal forma de transformação do dicl osulam no sol o évia microrganismos (Rodrigues \& Almeida, 1998)

O maior pH no sol o sob PD do quesob PC também pode ter contribuído para a maior degradação do diclosulam no PD, provavelmente por aumentar a atividade microbiana e a proporção de moléculas aniônicas, as quais se tornam mais polares e mais solúveis, e assim mais susceptíveis ao ataque microbiano. Esta diferença nos valores de $\mathrm{pH}$ entre os sol os sob dois sistemas de cultivo (Quadro 1) pode ser importante no comportamento das moléculas do diclosulam, que apresentam comportamento de ácido fraco, com valor de $\mathrm{p} K_{\mathrm{a}}(4,09)$. Com base no $\mathrm{p} K_{\mathrm{a}}$, a proporção de moléculas negativamente carregadas no PD (pH 5) deve ser $\sim 4$ vezes maior do que no PC (pH 4,4).

O maior conteúdo de matéria orgânica no PD também pode explicar, em parte, a maior dissi pação do did osulam nesse sistema decultivo, por aumentar

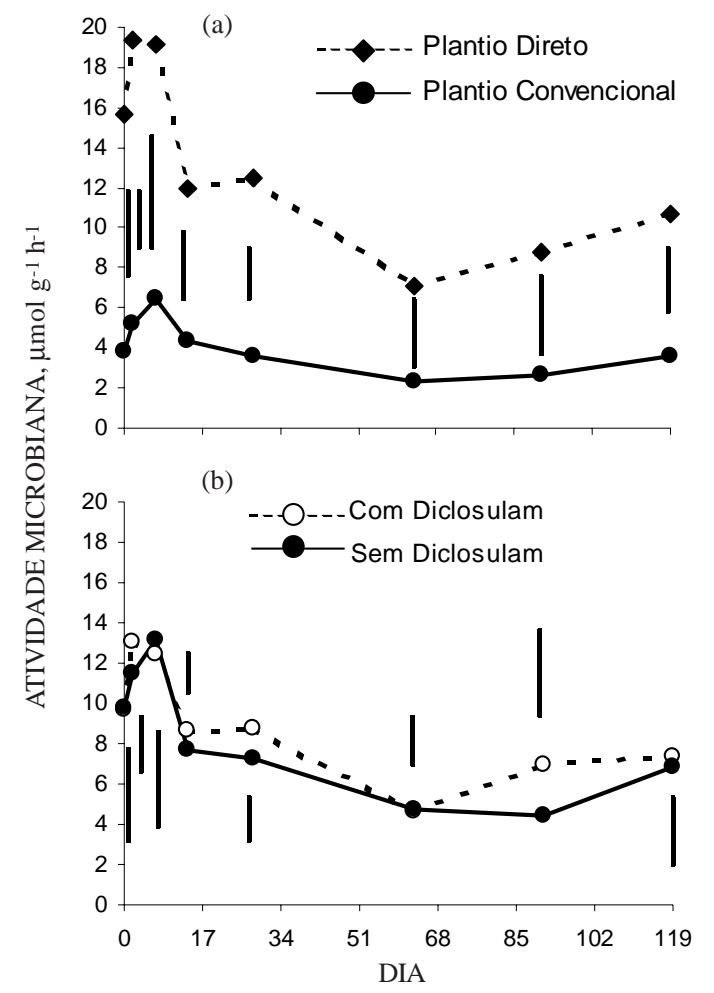

Figura 3. Atividade microbiana num Latossolo Vermelho distroférrico cultivado há 10 anos sob (a) plantio direto ou convencional e (b) com e sem aplicação de diclosulam. As barras verticais indicam a diferença mínima significativa (DMS) pelo teste t a 0,05. a formação da fração resíduo ligado do pesticida (Figura 2d). Neste caso, o fenômeno de sorção por interação hidrofóbica estaria, provavel mente, sendo mais importante que outros fenômenos desuperfície, como, por exemplo, as ligações el etrostáticas.

Do ponto de vista da molécula do diclosulam, embora este herbicida apresente hidrofobicidade dependente de $\mathrm{pH}$, a qual decresce com o aumento do mesmo, ela passa a ser importante para valores de pH superiores a 7 (Yoder et al., 2000). Desta forma, o fato de o sol o sob PC apresentar menor $\mathrm{pH}$ (Quadro 1) não constitui, provavelmente, um fator determinante na variação da interação hidrofóbica entre o pesticida e as substâncias húmicas do solo.

Por outrolado, segundo Martin-Neto et al . (1999), existem mudanças confor macionais das substâncias húmicas com a alteração do pH. Para menores valores de $\mathrm{pH}$, as substâncias húmicas apresentamse mais gl obulares, o que favorece a criação de sítios hidrofóbicos e, com isto, pode aumentar sua interação com o her bicida. No entanto, pel o fato de o sol o sob PC apresentar menor pH do queo sob PD (Quadro 1), os resultados obtidos neste trabal ho mostram que o efeito do conteúdo de $\mathrm{C}_{\text {org }}$ está sendo mais importante que o efeito do $\mathrm{pH}$ para a formação de resíduo ligado e, conseqüentemente, para a dissipação do diclosulam (F igura 2).

De acordo com Gamble et al. (2000), a formação de resíduo ligado pode apresentar duas fases distintas: uma fase rápida (aproximadamente $24 \mathrm{~h}$ ), provavel mente determinada por processos de superfície seguida de uma fase lenta, na qual a formação de resíduo ligado ocorre por difusão da molécula no interior das substâncias húmicas. Tal hi pótese, levantada por Gambleet al . (2000), também poderia ser aqui sugerida, visto que o aumento do tempo de contato entrea molécula ea fração col oi dal orgânica do solo, nos dois sistemas de cultivo, proporcionou uma redu ção na extração da mol écula, contribuindo, assim, com o aumento da formação de resíduo ligado (Figura $2 \mathrm{~d}$ ).

No entanto, essa redução também pode estar atrelada ao aumento da taxa de mineralização e metabolização do dicl osulam com o passar do tempo (Figuras 2b e2c). A degradação do d oransulam metil, uma mol écula pertencenteao mesmo grupo químico e estrutural mente semel hante ao diclosulam, foi estudada em vários sol os por Van Wesenbeeck et al. (1997). Naquele trabalho, foi aplicado o modelo exponencial bi-compartimentado e foi observado comportamento semel hante ao verificado neste estudo, mostrando a importância da formação de resíduo ligado para a dissi pação do pesticida eser a degradação muito menor quando a molécula encontra-se ligada.

A concentração dos metabólitos extraídos, nos dois sistemas de cultivo, aumentou com o tempo de contato (Figura 2c). O aumento da própria produção dos metabólitos pode ser atribuído ao seu menor 
contato com o solo (menor período de tempo que a molécula original), aliada ao fato de serem os metabólitos do diclosulam mais polares que a molécula original, o que os torna mais extraíveis (Yoder et al., 2000).

Os valores de relação de frente $\left(R_{f}\right)$ das ${ }^{14} \mathrm{C}$ moléculas contidas nos extratos, observadas nas placas de TLC por "radio-scanner", foram de 0,79 (molécula original) e 0,62 (metabólito não identificado pela falta de padrão analítico). Yoder et al. (2000) propuseram uma rota metabólica para a degradação do diclosulama partir dos metabólitos por eles identificados: aminosulfonil triazol pirimidina (ASTP), [n-(2,6-diclorofenil)-5-hidroxi-7-fluoro $(1,2,4)$-triazol o(1,5c)-pirimidina-2-sulfonamida] (5-OH-diclosulam) e [n-(2,6-diclorofenil)-5-hidroxi7-fluoro-8-cl oro-(1,2,4)-triazolo(1,5c)-pirimidina-2sulfonamida] (8-Cl-diclosulam). Entretanto, no presente estudo, considerando o local da radiomarcação da molécula, descarta-se a possibilidade de ser o metaból ito obtido $\left(R_{f}=0,62\right)$ o ASTP. Por outro lado, existe a possibilidade de que o metabólito aqui obtido seja tanto o5-OH-didosulam quanto o 8-Cl-diclosulam, ou atémesmo uma mistura dos dois, visto que ambos apresentam polaridade semel hante, o que poderia ter contribuído, de forma negativa, na separação dos dois metabólitos na placa.

No estudo da atividade mi crobiana, não foi obtida interação significativa entre os sistemas de cultivo e a aplicação ou não do herbicida. Analisando os fatores separadamente, além do efeito observado e já comentado do sistema de cultivo na atividade microbiana (Figura 3a), observou-se também que a aplicação do didosulam não apresentou efeito na atividade mi crobiana do solo, independentemente do sistema de cultivo (Figura 3b).

Os valores das constantes de Freundlich para sorção $\left(K_{\mathrm{f}}\right)$ foram similares para os sistemas de cultivo, 1,85 e 1,94 [( $\left.\left.\mathrm{mg} \mathrm{g}^{-1}\right)\left(\mathrm{mL} \mathrm{mg}^{-1}\right)^{\mathrm{N}}\right]$, para o PD e PC (Quadro 2), respectivamente. Esses valores caracterizam o dicl osulam como uma molécula com baixo potencial de sorção nesse solo. Entretanto, os resultados de resíduo ligado (Figura 2D) mostram que a energia de ligação aumenta com o aumento do tempo de contato entre o herbicida e o solo, tendo a percentagem de resíduo ligado variado de 1,9\% do total aplicado, no dia da aplicação, a $29,1 \%$, no final do experimento, para o PD, e de 1,8 a $23,6 \%$, para o PC. Esses resultados são, de certa forma, conflitantes e podem ser explicados pel o fato do teste de sorção apenas levar em consideração um tempo de equilíbrio.

Os valores de grau de linearidade das isotermas $(N)$ foram praticamente 1 para sor ção, o que sugere que o parâmetro de F reundl ich para sorção $\left(K_{f}\right)$ possa ser considerado como constante de partição linear $\left(K_{d}\right)$ (Quadro 2). Desta forma, os valores de $K_{f}$ obtidos neste experimento estão de acordo com os apresentados por Yoder et al. (2000) para a maioria dos solos estudados e são também similares aos coeficientes de sorção de outras sulfonamidas (Lenhman et al., 1992; Wolt et al., 1996).

Quadro 2. Valores dos parâmetros para sorção/dessorção e índice "Groundwater ubiquity score" (GUS) de diclosulam em Latossolo Vermelho distroférrico cultivado há 10 anos sob plantio direto (PD) ou convencional (PC)

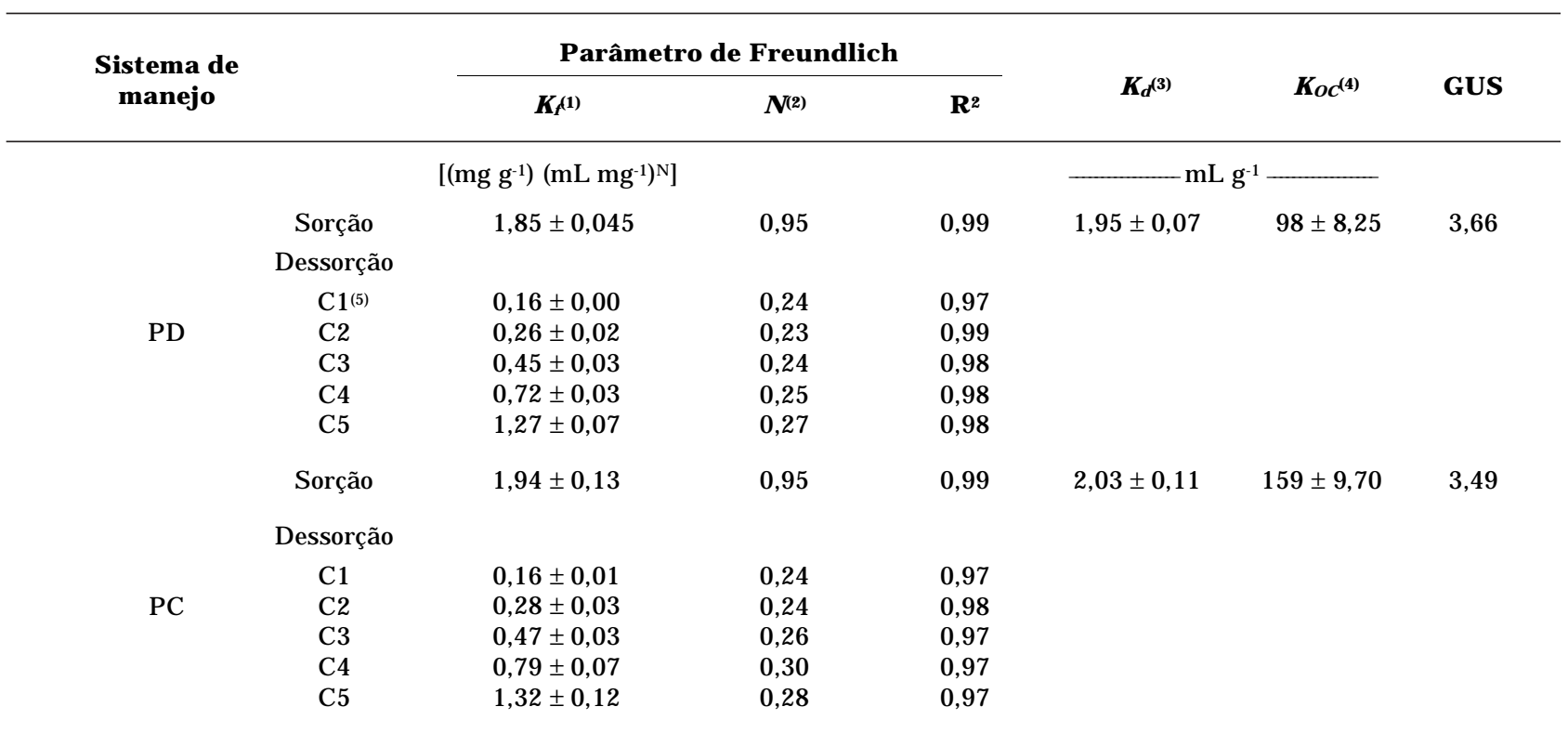

(1) Constante de Freundlich para sorção ou dessorção. ${ }^{(2)}$ Grau de linearidade da isoterma. ${ }^{(3)}$ Coeficiente de partição. ${ }^{(4)}$ Coeficiente de partição normalizado para carbono orgânico. ${ }^{(5)}$ Concentração inicial de diclosulam. 
Os valores de $N$ para dessorção foram inferiores aos de sorção (Quadro 2), indicando ter havido histerese. Isto indica que a dessorção real de diclosulam deve ser inferior à prevista pel os valores de $K_{f}$ (dessorção) fornecidos pelo modelo de Freundlich (Quadro 2).

O índice "Groundwater Ubiquity Score" (GUS) apresentou valores da ordem de 3,66 e 3,49, para os sol os sob PD e PC, respectivamente (Quadro 2). De acordo com Gustafson (1989), estes índices caracterizam o diclosulam, nesse solo, como uma molécula com potencial de lixiviação, o que é reflexo de sua meia-vida, entre 60 e 90 dias, e sua baixa sorção. Entretanto, o índice GUS fornece apenas uma estimativa grosseira da predição do movimento de um pesticida no solo, pois leva em consideração apenas os valores de $K_{O C}$ e da meia-vida, desconsiderando parâmetros fundamentais para lixiviação, tais como os rel acionados com as condições climáticas e estrutura do solo.

\section{CONCLUSÕES}

1. O sistema de manejo interferiu na dissipação do diclosulam, fazendo com que fosse maior no plantio direto do que no convencional.

2. A presença do diclosulam não afetou a atividade microbiana do solo em amostras provenientes de qualquer sistema de manejo.

3. O diclosulam apresentou baixa taxa de sorção ao sol o nos dois sistemas de manejo.

\section{AGRADE CIMENTOS}

À companhia Dow AgroSciences, pela concessão da mol écula radioativa e do padrão analítico.

\section{LITE RATURA CITADA}

BARTHA, R. \& PRAMER, D. Features of a flask and method for measuring the persistence and biological effects of pesticides in soil. Soil Sci., 100:68-70, 1965.

BOLLAG, J.M. \& LIU, S.Y. Biological transformation processes of pesticides. In: CHENG, H.H., ed. Pesticides in the soil environment: Processes, impacts, and modeling. 2.ed. Madison, Soil Science Society of America, 1990. p.169-211.

BRASIL. Ministério do I nterior. Manual detestes para avaliação da ecotoxicidade de agentes químicos. Brasília, MINTERSecretaria Especial do Meio Ambiente, 1988. 261p.

CAMARGO, O.A.; MONIZ, A.C.; J ORGE, J .A. \& VALADARES, J.M. Métodos de análise química, mineralógica e física de solos do Instituto Agronômico de Campinas. Campinas, Instituto Agronômico de Campinas, 1986. 94p. (Boletim Técnico, 106)
FREITAS, J.R.; NASCIMENTO FILHO, V.; VOSE, P.B. \& RUSCHEL, A.P. Estimativa da atividade da microflora heterotrófica do soloTRE usando respirometria com glicose${ }^{14} \mathrm{C}$. Energia Nuc. Agric., 1:123-130, 1979.

FÜHR, F. Non-extractable pesticides residues in soil. In: GREENHALG, R. \& ROBERTS, T.R., eds. Pesticide science and biotrchnology. Oxford, International Union of Pureand Applied Chemistry, 1987. p.381-389.

GAMBLE, D.S.; BRUCCOLERI,A.G.; LINDSAY, E.; LANGFORD, C.H. \& LEYS, G.A. Chlorothalonyl in a quartz sand soil: Speciation and kinetics. Environ. Sci. Technol., 34:120-124, 2000.

GUSTAFSON, D.I . Groundwater ubiquity score: a simple method for assessing pesticide leachability. Environ. Toxicol. Chem., 8:339-357, 1989

HORNSBY, A.G.; WAUCHOUPE, R.D. \& HERNER, A.E. Pesticide properties in the environment. New York, Springer-Verlag, 1995. 227p.

LAVORENTI, A. I dentificação de perigos de resíduos ligados de pesticidas em substâncias húmicas. In: ENCONTRO BRASILEIRO DE SUBSTÂNCIAS HÚMICAS, 2., São Carlos, 1997. Anais. São Carlos, EMBRAPA,1997. p.66-71.

LEHMANN， R.G.; MILLER，J.R.; FONTAINE， D.D.; LASKOWSKI, D.A.; HUNTER, J,H. \& CORDES, R.C. Degradation of a sulfonamide herbicide as a function of soil sorption. Weed Res., 32:197-205, 1992.

MARTIN-NETO, L.; FERREIRA, J.A.; NASCIMENTO, O.R.; TRAGHETTA, D.G.; VAZ, C.M.P. \& SIMOES, M.L. Interação herbicidas e substâncias húmicas: Estudos com espectroscopia e polarografia. In: ENCONTRO BRASILEIRO DE SUBSTÂNCIAS HÚMICAS, 3., Santa Maria, 1999. Anais. Santa Maria, Universidade Federal de Santa Maria, 1999. p.13-20.

RAIJ, B. van \& QUAGGIO, J.A. Métodos de análise de solos para fins de fertilidade. Campinas, Instituto Agronômico de Campinas, 1983. 31p. (Boletim Técnico, 81)

RODRIGUES, B.N. \& ALMEIDA, F.S. Guia de herbicidas. 4.ed. Londrina, Instituto Agronômico do Paraná, 1998. 648p.

SINGH, G.K. \& SHANER, D.L. Biosynthesis of branched chain amino acids: From test tube to field. Plant Cell., 7:935-944, 1995.

SPARKS, D.L. Kinetics of soil chemical processes. London, Academic Press, 1989. 210p.

Van WESENBEECK; ZABIK, I I. .; WOLT, J .D.; BORMETT, G.A. $\&$ ROBERTS, D.W. Field dissipation of chlorasulam-methyl at four sites in the the U.S. soybean market. J. Agric. Food Chem., 45:3299-3307, 1997.

WOLT, J.D.; SMITH, J .K.; SIMS, J.K. \& DUEBELBEIS, D.O. Products and kinetics of chlorasulam-methyl aerobic soil metabolism. J. Agric. Food. Chem., 44:324-332, 1996.

YODER, R.N.; HUSKIN, M.A.; KENNARD, L.M. \& ZABIK, J . Aerobic metabolism of diclosulam on U.S. and South American soils. J. Agric. Food Chem., 48:4335-4340, 2000. 